\title{
Isolation, technological characterization and in vitro probiotic evaluation of Lactococcus strains from traditional Turkish skin bag Tulum cheeses
}

\author{
Erhan Kazancıgil $^{1} \cdot$ Talha Demirci $^{1} \cdot$ Hale İnci Öztürk-Negiş ${ }^{2}$ (D) - Nihat Akın ${ }^{1}$ \\ Received: 9 April 2019 / Accepted: 22 August 2019 /Published online: 29 August 2019 \\ (C) Università degli studi di Milano 2019
}

\begin{abstract}
Purpose The present study was undertaken to evaluate in vitro prerequisite probiotic and technological characteristics of ten Lactococcus strains isolated from traditional goat skin bags of Tulum cheeses from the Central Taurus mountain range in Turkey. Methods All isolates were identified based on the nucleotide sequences of the 16S rRNA gene. Eight isolates belonged to Lactococcus lactis and two belonged to Lactococcus garvieae. Probiotic potential was determined from resistance to acid and bile salt, resistance to gastric and pancreatic juices, resistance to antibiotic, auto-aggregation, co-aggregation, diacetyl, hydrogen peroxide and exopolysaccharide productions. Technological properties were verified by alcohol, $\mathrm{NaCl}$ and hydrogen peroxide resistance and temperature tests.

Results L. lactis NTH7 displayed high growth at all alcohol concentrations while L. lactis NTH4 grew very well even at $\mathrm{NaCl}$ concentrations of $10 \%$. All strains showed to some extent resistance to acid and bile. Five strains exhibited desirable survival in gastric juice ( $\mathrm{pH}$ 2.0), while three strains survived in pancreatic juice ( $\mathrm{pH} \mathrm{8.0).} \mathrm{All} \mathrm{Lactococcus} \mathrm{isolates} \mathrm{were} \mathrm{sensitive} \mathrm{to}$ ampicillin, chloramphenicol, erythromycin, vancomycin, kanamycin, gentamycin and tetracycline. Also, only L. lactis NTH7 from among the isolates showed resistance against penicillin. L. lactis NTH10 and L. lactis NTH7 had higher auto-aggregation values in comparison with all other strains. All the strains demonstrated a co-aggregation ability against model food pathogens, particularly, L. lactis NTH10 which showed a superior ability with L. monocytogenes. All the ten strains produced $\mathrm{H}_{2} \mathrm{O}_{2}$ and exopolysaccharide (EPS); however, diacetyl production was detected for only four strains including L. lactis NTH10.

Conclusion These results demonstrate that the L. lactis NTH10 isolate could be regarded as a favorable probiotic candidate for future in vivo studies.
\end{abstract}

Keywords Probiotic $\cdot$ Technological characteristics $\cdot$ Lactococcus $\cdot$ Tulum cheese

\section{Introduction}

Lactic acid bacteria (LAB) are Gram-positive bacteria that naturally exist as endogenous microbiota in raw milk and in other food sources such as vegetables and meat. They play an important role as starter or adjunct cultures for the fermentation of foods. A large number of LAB strains have been

Hale İnci Öztürk-Negiș

inci.ozturk@gidatarim.edu.tr

1 Department of Food Engineering, University of Selcuk, 42050 Konya, Turkey

2 Department of Food Engineering, Konya Food and Agriculture University, 42080 Konya, Turkey isolated from different fermented foods, and selected strains have been used in industrial food fermentations (Adamberg et al. 2003). LAB have a significant effect on acidification, texture and sensorial properties of fermented foods such as yoghurt, cheese, pickle, sauerkraut, etc. Moreover, LAB constitute a large proportion of probiotic bacteria (Collins and Gibson 1999). Food grade LAB have been investigated for their probiotic potentials and are used as adjunct cultures in various food products (Rodgers 2008).

Probiotics are defined as living microorganisms that provide beneficial health effects to humans when they are consumed in sufficient amounts (FAO/WHO 2001). Potential health effects of probiotic bacteria involve lowering cholesterol and preventing or relieving symptoms of lactose intolerance, irritable bowel syndrome, hypertension, inflammatory bowel diseases, diarrhea and diabetes (Weichselbaum 2009; 
Ooi and Liong 2010). Therefore, foods containing probiotics are referred to as functional foods. The functional food industry has focused on the isolation of new probiotic strains with health-promoting benefits (Umer Khan 2014). In addition to its beneficial health effects, its technological features are also important for industrial use. In vitro tests such as antimicrobial activity, resistance to gastrointestinal conditions, acid and bile salt tolerance, etc., are usually carried out as a first approach (Kumar et al. 2015) in identifying potential probiotic microorganisms that can meet the increasing industrial demand (Das et al. 2016; Abushelaibi et al. 2017; Bengoa et al. 2018).

Tulum cheese is a variety of ripened cheese produced from raw milk. No starter culture is used in its production; thereby, its microbial content consists of the natural or wild microbiota of raw milk. Accordingly, a spontaneous fermentation occurs during Tulum cheese manufacturing. Based on previous studies, spontaneously fermented foods seem to be a good source of new LAB strains with potential probiotic attributes (Takeda et al. 2011; Tulumoğlu et al. 2014). Domingos-Lopes et al. (2017) reported that LAB strains isolated from raw cow milk cheese (Pico cheese) generated diacetyls and exopolysaccharides. In addition to this study, it was found that Lactococcus lactis strains isolated from Lighvan cheese, also a raw milk cheese, had antibacterial activity (Attar et al. 2018), while another study found that LAB strains isolated from raw sheep milk cheese were resistant to gastric juice, pancreatic juice and bile salt and had high acid tolerance (Meira et al. 2012).

Previous studies related to the determination of the LAB population of Tulum cheese were carried out for quality standardization and preserving the product characteristics (Gurses and Erdogan 2006; Cakmakci et al. 2008), but probiotic and technological properties of the isolates were not considered in these studies. Tulumoğlu et al. (2014), on the other hand, examined probiotic characteristics of Lactobacillus strains isolated from Tulum cheese. However, there are no previous studies in the literature about the probiotic and technological properties of Lactococcus strains isolated from Tulum cheese. The aims of this study were to isolate and investigate Lactococcus strains from Tulum cheese in order to provide a collection of LAB strains that could be utilized as starter or adjunct cultures for the food industry based on their defined technological and probiotic properties. In this context, diacetyl production, hydrogen peroxide production, exopolysaccharide production, auto-aggregation, co-aggregation, antibiotic resistance, acid tolerance, resistance to bile salt, and resistance to gastric and pancreatic juices tests were applied to assess the probiotic potential of the Lactococcus isolates. Moreover, the technological characteristics of the isolates were evaluated using alcohol resistance, $\mathrm{NaCl}$ resistance, hydrogen peroxide resistance and growth at different temperatures tests. Lactococcus strains isolated from Tulum cheese were identified by $16 \mathrm{~S}$ rRNA gene sequencing.

\section{Material and methods}

\section{Culture conditions}

All Lactococcus strains were grown in M17 broth (Merck) at $30{ }^{\circ} \mathrm{C}$ for $24 \mathrm{~h}$ under aerobic conditions. Indicator strains Escherichia coli ATCC 25922, Listeria monocytogenes ATCC 7644, Salmonella typhimurium ATCC 14028, Staphylococcus aureus ATCC 25923 and Bacillus cereus ATCC 14579 were used for antimicrobial and coaggregation analyses and were supplied from the Provincial Control Laboratory in Konya, Turkey. All indicator strains were incubated in Brain Heart Infusion broth (Merck) at $37{ }^{\circ} \mathrm{C}$ for $24 \mathrm{~h}$ under aerobic conditions. Purified isolates and indicator strains were stored at $-80{ }^{\circ} \mathrm{C}$ by adding $20 \%$ sterile glycerol $(v / v)$. The cultures were activated before use.

\section{Isolation of Lactococcus strains}

Lactococcus strains were isolated using the spread-plate and streaking methods on LM17 medium (Merck) supplemented with $5 \mathrm{~g} / \mathrm{l}$ of lactose (Randazzo et al. 2006). For this purpose, $10 \mathrm{~g}$ of a Tulum cheese sample was diluted in a 90-ml sodium citrate solution (2\%) (Merck) and homogenized with a Stomacher (HG400V, Mayo International, Italy). Serial dilutions were made and plated on LM17 medium. The plates were incubated at $30{ }^{\circ} \mathrm{C}$ for $48 \mathrm{~h}$ under aerobic conditions. After incubation, cultures were gathered randomly from plates. The cultures were then streaked over an agar surface of LM17 medium and incubated again under the same growth conditions. This process was repeated twice, and then, pure cultures were collected. The cultures were checked regularly for purity using a microscope. The pure cultures were transferred to the M17 broth to maintain their purity and stored under the above mentioned conditions.

\section{Molecular identification of Lactococcus isolates}

Isolated strains were identified by $16 \mathrm{~S}$ rRNA sequencing. In this context, F365 (5'-ACWCCTACGGGWGGCWGC-3') and R1064 (5'-AYCTCACGRCACGAGCTGAC-3') universal primers, designed from an invariant region in the $16 \mathrm{~S}$ rRNA sequences for LAB, were used in PCR amplification and were obtained from the Sentegen Biotech Co., Turkey. The PCR amplification was performed in a final $30-\mu$ reaction volume using a BioRAD thermal cycler $\left(\mathrm{T} 100^{\mathrm{TM}}\right.$, Foster City, California, USA).

For DNA extraction, activated stock cultures were left to incubate in LM17 agar at $37{ }^{\circ} \mathrm{C}$ for $48 \mathrm{~h}$ under aerobic conditions. At the end of the incubation, single colonies in the LM17 medium were suspended in sterile Eppendorf tubes containing $10 \mu \mathrm{l}$ of PCR-grade water. A $1-\mu \mathrm{l}$ aliquot of each sample suspension was transferred to an Eppendorf tube, and 
$21.3 \mu \mathrm{l}$ of PCR-grade water, $1.2 \mu \mathrm{l}$ of $\mathrm{MgCl}_{2}, 3 \mu \mathrm{l}$ of PCR buffer, $1 \mu \mathrm{l}$ of reverse primer, $1 \mu \mathrm{l}$ of forward primer, $0.5 \mu \mathrm{l}$ of Taq DNA polymerase and $1 \mu \mathrm{l}$ of dNTP solutions were added to produce a final $30-\mu$ PCR mixture volume. The chemicals used were supplied by Thermo Fisher Scientific.

The PCR conditions for the amplification procedure were as follows: initial denaturation at $95^{\circ} \mathrm{C}$ for $5 \mathrm{~min}, 35$ cycles of denaturation at $95{ }^{\circ} \mathrm{C}$ for $30 \mathrm{~s}$, primer annealing at $58^{\circ} \mathrm{C}$ for $30 \mathrm{~s}$ and extension at $72{ }^{\circ} \mathrm{C}$ for $45 \mathrm{~s}$ and one cycle of final extension at $72{ }^{\circ} \mathrm{C}$ for $10 \mathrm{~min}$. Presence of PCR products and their purity were verified by agarose gel electrophoresis. The PCR products were sent to Sentegen Biotech (Turkey) for purification and sequencing. Lactococcus strains were identified by comparing the sequence results with the DNA sequence database present at the National Centre for Biotechnology Information (NCBI) using the BLAST algorithm (http://ncbi.nlm.nih.gov/BLAST).

\section{Strain characteristics associated with probiotic potential}

\section{Tolerance to bile salt}

Bile salt resistance was determined according to the method of Sabir et al. (2010). An aliquot of $250 \mu \mathrm{l}$ of bacterial suspension ( $9 \log \mathrm{CFU} / \mathrm{ml}$ ) was inoculated into $5 \mathrm{ml}$ of sterile M17 broth and incubated at $37{ }^{\circ} \mathrm{C}$ for $24 \mathrm{~h}$. After incubation, bacterial cells were collected by centrifugation $(10,000 \mathrm{~g}, 10 \mathrm{~min}$, $4{ }^{\circ} \mathrm{C}$ ), and then washed thrice and resuspended in a phosphate buffer (PBS). A $0.1 \mathrm{ml}$ of bacterial suspension was added to $0.9 \mathrm{ml}$ of $0.15 \%, 0.3 \%$ and $0.5 \%$ bile salt solutions and control solution (i.e. without bile salt) and incubated at $37^{\circ} \mathrm{C}$ for $2 \mathrm{~h}$. Following the incubation period, bacterial growth was observed by recording absorbance at $600 \mathrm{~nm}$ and results were stated as optical density.

\section{Resistance against acid}

Resistance under different acidic conditions was evaluated using a bacterial suspension $(\sim 9 \log \mathrm{CFU} / \mathrm{ml})$ in sterile distilled water adjusted to $\mathrm{pH}$ levels of 1.0, 2.0 and 3.0 by the addition of $\mathrm{HCl}$ as defined by Mishra and Prasad (2005). Sterile distilled water with a $\mathrm{pH} 6.4$ was used as a control. Following the $\mathrm{pH}$ application, $1 \mathrm{ml}$ of each $\mathrm{pH}$ solution was extracted after $2 \mathrm{~h}$ and bacterial growth was monitored by measuring absorbance at $600 \mathrm{~nm}$. Results were given as optical density.

\section{Tolerance to gastric and pancreatic juices}

Simulated gastric and pancreatic digestions were analyzed using the methods of Bautista-Gallego et al. (2013) with slight modifications. Simulated gastric juice was prepared in a solution at pH 2.0 containing $\mathrm{KH}_{2} \mathrm{PO}_{4}(0.60 \mathrm{~g} / \mathrm{l}), \mathrm{KCl}$ $(0.37 \mathrm{~g} / \mathrm{l}), \mathrm{NaCl}(2.05 \mathrm{~g} / \mathrm{l})$ and $\mathrm{CaCl}_{2}(0.11 \mathrm{~g} / \mathrm{l})$. Prior to use, the solution was sterilized, and then, lysozyme $(0.01 \mathrm{~g} / \mathrm{l})$ and pepsin $(13.3 \mathrm{mg} / \mathrm{l})$ enzymes were added. In the meantime, activated cultures were centrifuged $(10,000 \times g, 10 \mathrm{~min})$ and washed twice with PBS buffer ( $\mathrm{pH} 7.0)$. The culture pellets were then resuspended into the simulated gastric juice to give a final concentration of $8 \log \mathrm{CFU} / \mathrm{ml}$ and incubated at $37^{\circ} \mathrm{C}$ for $3 \mathrm{~h}$. Serial dilutions of the incubated gastric juices were plated on M17 agar and enumerated after incubation for 35 days at $30^{\circ} \mathrm{C}$.

Simulated pancreatic juice was formulated in a solution at pH 8.0 consisting of $\mathrm{Na}_{2} \mathrm{HPO}_{4} \cdot 7 \mathrm{H}_{2} \mathrm{O}(50.81 \mathrm{~g} / \mathrm{l}), \mathrm{NaCl}(8.5 \mathrm{~g} /$ 1), pancreatin $(0.1 \mathrm{~g} / \mathrm{l})$ and bile $(3 \mathrm{~g} / \mathrm{l})$. For sterilization, the solution was passed through a $0.22-\mu \mathrm{M}$ membrane filter. At the same time, activated cultures were harvested by centrifugation at $10,000 \mathrm{~g}$ for $10 \mathrm{~min}$ and washed twice with PBS buffer ( $\mathrm{pH}$ 7.0). The culture pellets were then resuspended into the simulated pancreatic juice to provide a final concentration of $8 \log \mathrm{CFU} / \mathrm{ml}$ and incubated at $37{ }^{\circ} \mathrm{C}$ overnight. After the incubation, serial dilutions of the cultures were plated on M17 and counted following incubation at $30{ }^{\circ} \mathrm{C}$ for $3-$ 5 days. The culture pellets resuspended in PBS ( $\mathrm{pH} 7.0)$ were used as control for these tests. The tolerances of the strains to simulated gastric and intestinal transits were evaluated by comparison with counts of viable cells resuspended in PBS and incubated in gastric and pancreatic juices. Results were expressed as survival rate during gastric and pancreatic digestion.

\section{Antibiotic resistance}

Antibiotic resistance of isolates was determined based on the agar disc diffusion method described by Charteris et al. (1998a). Lactococcus strains were activated in M17 broth overnight. All isolates were assessed for their susceptibility to ampicillin $(10 \mu \mathrm{g} / \mathrm{disc})$, chloramphenicol $(30 \mu \mathrm{g} / \mathrm{disc})$, erythromycin $(15 \mu \mathrm{g} /$ disc $)$, vancomycin (30 $\mu \mathrm{g} /$ disc), kanamycin $(30 \mu \mathrm{g} / \mathrm{disc})$, gentamycin $(10 \mu \mathrm{g} / \mathrm{disc})$, penicillin (10 IU/disc), streptomycin $(10 \mu \mathrm{g} / \mathrm{disc})$ and tetracycline (30 $\mu \mathrm{g} / \mathrm{disc})$. For evaluating the antibiotic resistance, $100 \mu \mathrm{l}$ of an activated culture was spread on M17 agar and allowed to get absorbed. Thereafter, commercial antibiotic discs (Bioanalyse) were placed on the inoculated plates with sterile conditions and incubated at $37^{\circ} \mathrm{C}$ for $24 \mathrm{~h}$. After incubation, the diameter ( $\mathrm{mm}$ ) of inhibition zones was measured. Results were evaluated as sensitive, intermediate sensitive and resistant considering the zone diameters specified by Khemariya et al. (2013). If the diameter of the inhibition zone was between the range of 10 and $35 \mathrm{~mm}$ or smaller than $10 \mathrm{~mm}$, the strain was defined as sensitive or intermediate sensitive, respectively. Also, the absence of the inhibition zone was evaluated as resistant. 


\section{Auto-aggregation and co-aggregation}

Abilities of the Lactococcus strains to aggregate with each other (auto-aggregation) and with pathogens (coaggregation) were analyzed as detailed by Kos et al. (2003). Activated cultures were gathered by centrifugation at $5000 \mathrm{~g}$ for $15 \mathrm{~min}$ and washed twice in PBS. The harvested cultures were then resuspended in PBS to give viable counts of $8 \log$ $\mathrm{CFU} / \mathrm{ml}$. An aliquot of $4 \mathrm{ml}$ of the culture suspension was resuspended by the use of a vortex for $10 \mathrm{~s}$ and autoaggregation was observed during $24 \mathrm{~h}$ of incubation at room temperature. At different time intervals $(0,1,2$ and $24 \mathrm{~h})$, $100 \mu \mathrm{l}$ of the suspension was transferred into another vial containing $3.9 \mathrm{ml}$ of PBS and absorbance (A) was calculated at $600 \mathrm{~nm}$. The auto-aggregation percentage was determined as $1-\left(A_{\mathrm{t}} / A_{0}\right) \times 100$, where $A_{\mathrm{t}}$ stands for the absorbance at time 1,2 or $24 \mathrm{~h}$ and $A_{0}$ stands for the absorbance at time 0 .

Co-aggregation of the Lactococcus strains against five different pathogens was also assessed. For this purpose, $2 \mathrm{ml}$ of each Lactococcus strains was mixed with $2 \mathrm{ml}$ of each pathogen and this bacterial mix was incubated for $24 \mathrm{~h}$ at room temperature. At the same time, control tubes were prepared separately containing $4 \mathrm{ml}$ of each bacterial suspension. Samples were taken at different time intervals as in the autoaggregation assay and absorbance (A) of the suspensions at $600 \mathrm{~nm}$ was measured. Co-aggregation percentage was calculated using the following equation:

Co-aggregation $(\%)=\frac{((A a+A b) / 2)-A(a+b)}{(A a+A b) / 2} \times 100$

where $a$ and $b$ represent each of the two strains in the control tubes and $a+b$ represents the bacterial mixture.

\section{Exopolysaccharide production}

Exopolysaccharide (EPS) production from the Lactococcus strains was determined using the method of Van GeelSchutten et al. (1998). Cultures were inoculated in $20 \mathrm{ml}$ of M17 broth containing 2\% glucose $(w / v)$ and incubated for 3 days at $37^{\circ} \mathrm{C}$. Following incubation, the suspensions were centrifuged at $6000 \mathrm{~g}$ for $20 \mathrm{~min}$ to remove the bacterial cells. For precipitation of EPS, a 2:1 volume of cold ethanol (95\%, $v / v)$ to supernatant was prepared. EPS precipitates were filtered under vacuum and evaporated at $60{ }^{\circ} \mathrm{C}$. The EPS production from Lactococcus strains was determined by measuring the weights of the dried samples. The results were given as positive or negative for EPS production.

\section{Diacetyl production}

Activated cultures were centrifuged at $4000 \mathrm{rpm}$ for $15 \mathrm{~min}$, washed with PBS and the pellet was resuspended in PBS. The bacterial suspension was inoculated (1\%) in $10 \mathrm{ml}$ of UHT milk and incubated for $24 \mathrm{~h}$ at $30{ }^{\circ} \mathrm{C}$. Thereafter, $1 \mathrm{ml}$ of bacterial suspension was mixed with $0.5 \mathrm{ml}$ of $\mathrm{KOH}(16 \%$, $w / v)$ and $\alpha$-naphthol $(1 \%, w / v)$ solution and subsequently left in incubation at $37{ }^{\circ} \mathrm{C}$ for $10 \mathrm{~min}$. Diacetyl production was observed by the occurrence of a red ring at the top of the tubes (Ribeiro et al. 2014). Depending on the red ring formed, the results were expressed as positive or negative in terms of diacetyl production.

\section{Hydrogen peroxide production}

Hydrogen peroxide $\left(\mathrm{H}_{2} \mathrm{O}_{2}\right)$ production was analyzed spectrophotometrically according to the method of Patrick and Wagner (1949) with some modifications. Active cultures were inoculated (2\%) into M17 broth and incubated for $42 \mathrm{~h}$ at $35^{\circ} \mathrm{C}$. Following the incubation, $10 \mu \mathrm{l}$ of culture suspension was mixed with $2.0 \mathrm{ml}$ of hydrochloric acid, $0.2 \mathrm{ml}$ of ammonium molybdate in $1 \mathrm{M}$ sulfuric acid and $0.2 \mathrm{ml}$ of potassium iodide. After the mixture was allowed to stand for $20 \mathrm{~min}$, its absorbance was measured at $400 \mathrm{~nm}$. The same procedures were repeated using $\mathrm{H}_{2} \mathrm{O}_{2}$ with concentrations ranging from 1 to $10 \mu \mathrm{g} / \mathrm{ml}$ instead of sample to create a standard curve. The $\mathrm{H}_{2} \mathrm{O}_{2}$ production from Lactococcus strains was determined by utilizing the standard curve and the results were evaluated as positive or negative with regards to $\mathrm{H}_{2} \mathrm{O}_{2}$ production.

\section{Technological characterization}

\section{Alcohol resistance}

Alcohol tolerance analysis was applied by modifying the method of G-Alegría et al. (2004). Activated cultures were inoculated into a M17 broth supplemented with different ethanol concentrations $(3,6,12$ and $15 \%)$ and incubated at $30^{\circ} \mathrm{C}$ for $24-48 \mathrm{~h}$. Bacterial growth was assessed by observing turbidity.

\section{$\mathrm{H}_{2} \mathrm{O}_{2}$ resistance}

$\mathrm{H}_{2} \mathrm{O}_{2}$ tolerance of activated cultures was analyzed using the method of Li et al. (2012). The cultures were inoculated at $1 \%$ into M17 broth consisting of $0.4,0.7$ and $1.0 \mathrm{mM} \mathrm{H}_{2} \mathrm{O}_{2}(30 \%)$ and incubated for $8 \mathrm{~h}$ at $37^{\circ} \mathrm{C}$. Cell growth was determined spectrophotometrically at $600 \mathrm{~nm}$. Results were expressed as optical density.

\section{Growth at different temperatures}

Ability to grow at various temperatures was evaluated by modifying the method of Badis et al. (2004). Bacterial growth was assessed visually in M17 broth after incubation for 5 days at $4{ }^{\circ} \mathrm{C}, 15{ }^{\circ} \mathrm{C}$ and $45^{\circ} \mathrm{C}$. 


\section{$\mathrm{NaCl}$ resistance}

Tolerance of the Lactococcus cultures towards $\mathrm{NaCl}$ was determined according to the modified method of Hoque et al. (2010). Activated cultures were inoculated into M17 broth adjusted with various $\mathrm{NaCl}$ concentrations $(0,4,6.5$ and $10 \%$ ) and incubated at $37{ }^{\circ} \mathrm{C}$ for 7 days. After incubation, bacterial growth was evaluated by visual observation.

\section{Statistical analysis}

All data were given as the mean and standard deviation of two observations. The results were subjected to one-way ANOVA in Minitab software version 17 (State College, USA) to determine significant differences between means of bacterial cultures and treatments. The means of results were compared with the Tukey test with a confidence interval set at $95 \%$.

\section{Results and discussion}

\section{Identification of Lactococcuss strains by 16S rRNA sequencing}

Ten Lactococcus strains from Tulum cheese were identified using 16S rRNA sequencing (Table 1). Alignments were performed utilizing the BLAST algorithm. Based on molecular identification, L. garvieae NTH1 (99\%), L. garvieae NTH2 (99\%), L. lactis NTH3 (99\%), L. lactis NTH4 (99\%), L. lactis NTH5 (99\%), L. lactis NTH6 (99\%), L. lactis NTH7 (99\%), L. lactis NTH8 (99\%), L. lactis NTH9 (99\%) and L. lactis NTH10 (99\%) were determined. Among the identified Lactococcus strains, L. lactis species was seen to be dominant and it constituted $80 \%$ of the designated strains. Likewise, Lopez-Diaz et al. (2000) noticed that L. lactis had the highest share in isolates in traditional Spanish cheese.

\section{Tolerance of Lactococcus strains at different bile concentrations}

Bile salt tolerance is a fundamental parameter for bacterial colonization and viability in the small intestine and colon (Tambekar and Bhutada 2010). Bile salt resistances of isolated Lactococcus strains are shown in Table 2. Compared to their relevant control, L. garvieae NTH1, L. lactis NTH6, L. garvieae NTH2, L. lactis NTH8 and L. lactis NTH10 showed dramatic decrease in their population against increased bile salt concentration $(p<0.05)$. In the meantime, exposure of L. lactis NTH3, L. lactis NTH4, L. lactis NTH5 and L. lactis NTH7 to $0.5 \%$ bile salt resulted in a significant decrease in their viable cell counts, while lower bile salt concentrations were not effective on their viability. Among the Lactococcus isolates, L. lactis NTH9 presented relatively high tolerance to the 2-h incubation under all bile salt concentrations as compared to the others. Moreover, there was no statistically significant decrease in its viable cell count at $0.3 \%$ bile salt. Generally, the bile concentration of the intestinal environment is $0.3 \%$ (Prasad et al. 1998).

\section{Acid tolerance}

The $\mathrm{pH}$ of the human stomach varies between 1.5 and 4.5 depending on the food consumption, and food can stay in the stomach for 2-3 h during digestion (Bao et al. 2010). Table 3 shows acid tolerances of ten Lactococcus isolates under incubation at $\mathrm{pH} 1.0,2.0$ and 3.0 for 2 h. L. lactis NTH4, L. lactis NTH6, L. lactis NTH8, L. lactis NTH9 and L. lactis NTH10 were highly tolerant strains against acid due to their ability to maintain their viable cell counts even in low $\mathrm{pH}$ conditions $(p>0.05)$. Kimoto et al. (1999) reported that the growth of the NIAI 527 strain from their L. lactis subsp. lactis isolates was not affected by low $\mathrm{pH}$. However, in this study, other strains did show variable susceptibility to different $\mathrm{pH}$ levels, with a dramatic growth decrease at $\mathrm{pH} 1.0$ $(p<0.05)$. This came as no surprise given the multitude of studies that have observed that low $\mathrm{pH}$ levels adversely affect the growth of lactic acid bacteria and that acid tolerance changes from strain to strain (Sabir et al. 2010; Shehata et al. 2016; Abushelaibi et al. 2017).

At $\mathrm{pH}$ 1.0, with the exception of L. garvieae NTH1 and L. lactis NTH3, the growth of all other strains was similar, and their acid tolerances were higher than L. garvieae NTH1 and L. lactis NTH3. Furthermore, at a pH of 2.0, which mimics the $\mathrm{pH}$ of the stomach, the most resistant strain was determined to be L. lactis NTH9. Along with the data on bile salt resistance, this result supports the probiotic potential of L. lactis NTH9. Although the strain with the highest acid tolerance at $\mathrm{pH} 3.0$ was determined to be L. lactis NTH7, the difference between the acid tolerances of L. lactis NTH7 and L. lactis NTH9 can be considered statistically insignificant. Considering the stomach conditions, resistance against acid is a crucial characteristic for each potential probiotic organism. This feature allows them to be used as dietary adjuncts because they can maintain their viability in foods with high acidity (Chalas et al. 2016).

\section{Survival rates of Lactococcus strains during simulated gastric and intestinal transit}

The exposure of Lactococcus strains to simulated gastric juice for $3 \mathrm{~h}$ caused complete loss of viability in the strains with the exception of $L$. garvieae NTH1, L. lactis NTH4, L. garvieae NTH2, L. lactis NTH8 and L. lactis NTH10 (Table 4). Accordingly, L. lactis NTH3, L. lactis NTH5, L. lactis NTH6, L. lactis NTH7 and L. lactis NTH9 strains were detected to be sensitive against gastric conditions. 
Table 1 Lactococcus isolates identified by $16 \mathrm{~S}$ rRNA gene sequencing and their GenBank accession numbers adapted from NCBI-BLAST

\begin{tabular}{llll}
\hline Isolates & Closest known relative (strain No) & Identification \% & GenBank accession No \\
\hline NTH1 & L. garvieae (KE12) & 99 & HM573320.1 \\
NTH2 & L. garvieae (CAU1397) & 99 & MF429549.1 \\
NTH3 & L. lactis (C13) & 99 & JN942105.1 \\
NTH4 & L. lactis (T0625) & 99 & EU104368.1 \\
NTH5 & L. lactis (RPWL3) & 99 & MF185375.1 \\
NTH6 & L. lactis (SNNU0274) & 99 & KX752895.1 \\
NTH7 & L. lactis (NM45) & 99 & HM218209.1 \\
NTH8 & L. lactis (FM19LAB) & 99 & MF480428.1 \\
NTH9 & L. lactis (RCB1008) & 99 & KT261220.1 \\
NTH10 & L. lactis (CAU1157) & 99 & MF582909.1 \\
\hline
\end{tabular}

L. garvieae NTH1 (27.42\%), L. garvieae NTH2 (38.97\%), L. lactis NTH4 (21.23\%), L. lactis NTH8 (24.56\%) and L. lactis NTH10 (33.28\%) presented appreciable survival rates. Considering that the viable counts of probiotic bacteria exposed to gastric juice were decreased approximately 5-6 $\log$ (Vinderola and Reinheimer 2003), the survival rates determined between 21 and $39 \%$ against gastric juice is satisfactory in terms of probiotic potential. Moreover, L. garvieae NTH2 was evaluated as the most resistant strain to gastric transit. Even though lactococci were reported to be more sensitive than lactobacilli against gastric juice (Faye et al. 2012), the survival rate of $L$. garvieae NTH2 was determined to be higher than the Lactobacillus fermentum studied by Charteris et al. (1998b).

Most of the Lactococcus isolates were found to be sensitive to intestinal conditions (Table 4). Das et al.
(2016) reported that viable counts of lactic acid bacteria considerably decrease in intestinal juice. However, L. garvieae $\mathrm{NTH} 2$, L. lactis $\mathrm{NTH} 3$ and L. lactis NTH8 with $27.75 \%, 17.39 \%$ and $19.25 \%$ survival rates, respectively, exhibited tolerance to the pancreatic juice. Interestingly, L. garvieae NTH2 and L. lactis NTH8 showed resistance to pancreatic juice as well as gastric juice, L. garvieae NTH2 was detected as the most tolerant strain to pancreatic juice. This case could partially ensure that these strains survive in the gastrointestinal tract. However, performing these tests separately for gastrointestinal transit evaluation has some limitations compared to the continuous system. Therefore, for further evaluation of gastrointestinal conditions, bacteria which exhibited probiotic potential need to be tested in vitro analyses with continuous system.
Table 2 Tolerance of Lactococcus strains at different bile concentrations

\begin{tabular}{|c|c|c|c|c|}
\hline \multirow[t]{2}{*}{ Isolates } & \multicolumn{4}{|c|}{ Bile concentration (\%) } \\
\hline & 0 & 0.15 & 0.30 & 0.50 \\
\hline \multicolumn{5}{|c|}{ L. garvieae } \\
\hline NTH1 & $0.109 \pm 0.001^{\mathrm{ab}, \mathrm{a}}$ & $0.089 \pm 0.007^{\mathrm{cd}, \mathrm{b}}$ & $0.067 \pm 0.007^{\mathrm{c}, \mathrm{c}}$ & $0.035 \pm 0.005^{\mathrm{cd}, \mathrm{d}}$ \\
\hline NTH2 & $0.096 \pm 0.011^{\mathrm{c}, \mathrm{a}}$ & $0.078 \pm 0.003^{\mathrm{d}, \mathrm{b}}$ & $0.059 \pm 0.001^{\mathrm{c}, \mathrm{c}}$ & $0.044 \pm 0.001^{\mathrm{c}, \mathrm{d}}$ \\
\hline \multicolumn{5}{|l|}{ L. lactis } \\
\hline NTH3 & $0.057 \pm 0.003^{\mathrm{d}, \mathrm{a}}$ & $0.048 \pm 0.007^{\mathrm{e}, \mathrm{a}}$ & $0.048 \pm 0.007^{\mathrm{d}, \mathrm{a}}$ & $0.024 \pm 0.007^{\mathrm{de}, \mathrm{b}}$ \\
\hline NTH4 & $0.028 \pm 0.004^{\mathrm{e}, \mathrm{a}}$ & $0.023 \pm 0.002^{\mathrm{f}, \mathrm{ab}}$ & $0.018 \pm 0.001^{\mathrm{e}, \mathrm{ab}}$ & $0.009 \pm 0.001^{\mathrm{f}, \mathrm{b}}$ \\
\hline NTH5 & $0.024 \pm 0.002^{\mathrm{e}, \mathrm{a}}$ & $0.017 \pm 0.000^{\mathrm{f}, \mathrm{ab}}$ & $0.011 \pm 0.001^{\mathrm{e}, \mathrm{bc}}$ & $0.004 \pm 0.000^{\mathrm{f}, \mathrm{c}}$ \\
\hline NTH6 & $0.133 \pm 0.007^{\mathrm{a}, \mathrm{a}}$ & $0.098 \pm 0.002^{\mathrm{bc}, \mathrm{b}}$ & $0.067 \pm 0.002^{\mathrm{c}, \mathrm{c}}$ & $0.033 \pm 0.001^{\text {cde, } d}$ \\
\hline NTH7 & $0.125 \pm 0.005^{\mathrm{ab}, \mathrm{a}}$ & $0.108 \pm 0.001^{\mathrm{ab}, \mathrm{ab}}$ & $0.087 \pm 0.002^{\mathrm{b}, \mathrm{bc}}$ & $0.057 \pm 0.002^{\mathrm{b}, \mathrm{c}}$ \\
\hline NTH8 & $0.092 \pm 0.008^{\mathrm{c}, \mathrm{a}}$ & $0.081 \pm 0.001^{\mathrm{d}, \mathrm{b}}$ & $0.049 \pm 0.000^{\mathrm{d}, \mathrm{c}}$ & $0.022 \pm 0.000^{\mathrm{e}, \mathrm{d}}$ \\
\hline NTH9 & $0.134 \pm 0.018^{\mathrm{a}, \mathrm{a}}$ & $0.118 \pm 0.002^{\mathrm{a}, \mathrm{ab}}$ & $0.107 \pm 0.002^{\mathrm{a}, \mathrm{b}}$ & $0.094 \pm 0.004^{\mathrm{a}, \mathrm{b}}$ \\
\hline NTH10 & $0.026 \pm 0.002^{\mathrm{e}, \mathrm{a}}$ & $0.021 \pm 0.000^{\mathrm{f}, \mathrm{b}}$ & $0.014 \pm 0.001^{\mathrm{e}, \mathrm{c}}$ & $0.008 \pm 0.001^{\mathrm{f}, \mathrm{d}}$ \\
\hline
\end{tabular}

Results are given as optical density at $600 \mathrm{~nm}$

Different letters in the same row and column are significantly different $(P<0.05)$

First letters present differences between the strains and second letters demonstrate the differences between the bile concentrations

$n s$ not significantly different 
Table 3 Acid tolerances of Lactococcus strains at different $\mathrm{pH}$ conditions for $2 \mathrm{~h}$

\begin{tabular}{lllll}
\hline Isolates & Control $^{1}$ & $\mathrm{pH} 1.0$ & $\mathrm{pH} 2.0$ & $\mathrm{pH} 3.0$ \\
\hline L. garvieae & & & & \\
NTH1 & $0.056 \pm 0.011^{\mathrm{d}, \mathrm{a}}$ & $0.024 \pm 0.004^{\mathrm{b}, \mathrm{b}}$ & $0.033 \pm 0.009^{\mathrm{c}, \mathrm{ab}}$ & $0.041 \pm 0.018^{\mathrm{c}, \mathrm{ab}}$ \\
NTH2 & $0.220 \pm 0.021^{\mathrm{ab}, \mathrm{a}}$ & $0.135 \pm 0.035^{\mathrm{a}, \mathrm{b}}$ & $0.182 \pm 0.017^{\mathrm{b}, \mathrm{ab}}$ & $0.197 \pm 0.016^{\mathrm{b}, \mathrm{a}}$ \\
L. lactis & & & \\
NTH3 & $0.113 \pm 0.017^{\mathrm{c}, \mathrm{a}}$ & $0.022 \pm 0.012^{\mathrm{b}, \mathrm{c}}$ & $0.056 \pm 0.023^{\mathrm{c}, \mathrm{bc}}$ & $0.071 \pm 0.013^{\mathrm{c}, \mathrm{ab}}$ \\
NTH4 & $0.190 \pm 0.019^{\mathrm{bc}, \mathrm{ns}}$ & $0.162 \pm 0.017^{\mathrm{a}, \mathrm{ns}}$ & $0.188 \pm 0.011^{\mathrm{ab}, \mathrm{ns}}$ & $0.211 \pm 0.047^{\mathrm{ab}, \mathrm{ns}}$ \\
NTH5 & $0.210 \pm 0.022^{\mathrm{ab}, \mathrm{a}}$ & $0.143 \pm 0.023^{\mathrm{a}, \mathrm{b}}$ & $0.220 \pm 0.019^{\mathrm{ab}, \mathrm{a}}$ & $0.227 \pm 0.019^{\mathrm{ab}, \mathrm{a}}$ \\
NTH6 & $0.201 \pm 0.027^{\mathrm{ab}, \mathrm{ns}}$ & $0.163 \pm 0.019^{\mathrm{a}, \mathrm{ns}}$ & $0.203 \pm 0.011^{\mathrm{ab}, \mathrm{ns}}$ & $0.217 \pm 0.038^{\mathrm{ab}, \mathrm{ns}}$ \\
NTH7 & $0.274 \pm 0.038^{\mathrm{a}, \mathrm{a}}$ & $0.177 \pm 0.037^{\mathrm{a}, \mathrm{b}}$ & $0.202 \pm 0.022^{\mathrm{ab}, \mathrm{ab}}$ & $0.275 \pm 0.022^{\mathrm{a}, \mathrm{a}}$ \\
NTH8 & $0.228 \pm 0.045^{\mathrm{ab}, \mathrm{ns}}$ & $0.178 \pm 0.041^{\mathrm{a}, \mathrm{ns}}$ & $0.186 \pm 0.038^{\mathrm{ab}, \mathrm{ns}}$ & $0.235 \pm 0.017^{\mathrm{ab}, \mathrm{ns}}$ \\
NTH9 & $0.239 \pm 0.016^{\mathrm{ab}, \mathrm{ns}}$ & $0.207 \pm 0.016^{\mathrm{a}, \mathrm{ns}}$ & $0.241 \pm 0.016^{\mathrm{a}, \mathrm{ns}}$ & $0.207 \pm 0.013^{\mathrm{ab}, \mathrm{ns}}$ \\
NTH10 & $0.217 \pm 0.025^{\mathrm{ab}, \mathrm{ns}}$ & $0.187 \pm 0.022^{\mathrm{a}, \mathrm{ns}}$ & $0.201 \pm 0.013^{\mathrm{ab}, \mathrm{ns}}$ & $0.228 \pm 0.015^{\mathrm{ab}, \mathrm{ns}}$ \\
\hline
\end{tabular}

Results are given as optical density at $600 \mathrm{~nm}$

${ }^{1}$ Distilled water with a $\mathrm{pH} 6.4$ was used as a control

Different letters in the same row and column are significantly different $(P<0.05)$

First letters present differences between the strains and second letters demonstrate the differences between the $\mathrm{pH}$ conditions

$n s$ not significantly different

\section{Susceptibility to different antibiotics}

The determination of antibiotic resistance of strains with probiotic potential is of prime importance. Some bacteria may act as hosts of antibiotic resistance genes, which can be transferred to pathogenic or other bacteria in their environment (Danielsen and Wind 2003). The susceptibility results of Lactococcus strains to nine different antibiotics are presented in Table 5. All the Lactococcus isolates were found to be sensitive to ampicillin, chloramphenicol, erythromycin,

Table 4 Survival rates of Lactococcus strains during simulated gastric and intestinal transit

\begin{tabular}{lll}
\hline Isolates & \multicolumn{2}{l}{ Survival rate (\%) } \\
\cline { 2 - 3 } & Gastric juice (pH 2.0) & Pancreatic juice (pH 8.0) \\
\hline L. garvieae & & \\
NTH1 & 27.42 & NG \\
NTH2 & 38.97 & 27.75 \\
L. lactis & & \\
NTH3 & NG & 17.39 \\
NTH4 & 21.23 & NG \\
NTH5 & NG & NG \\
NTH6 & NG & NG \\
NTH7 & NG & NG \\
NTH8 & 24.56 & 19.25 \\
NTH9 & NG & NG \\
NTH10 & 33.28 & NG \\
\hline
\end{tabular}

$N G$ no growth vancomycin, kanamycin, gentamycin and tetracycline. Likewise, Domingos-Lopes et al. (2017) reported that L. lactis and L. garvieae strains isolated from raw cow milk were sensitive to chloramphenicol, gentamycin, erythromycin, kanamycin, tetracycline and vancomycin. Besides,

Table 5 Antibiotic susceptibility of Lactococcus strains against nine different antibiotics

\begin{tabular}{llllllllll}
\hline Isolates & \multicolumn{2}{l}{ Inhibition zone $(\mathrm{mm})^{\mathrm{a}}$} & & & & & \\
\cline { 2 - 9 } & Amp & Chl & Ery & Van & Kan & Gen & Pen & Str & Tet \\
\hline L. garvieae & & & & & & & & & \\
NTH1 & 29 & 21 & 17 & 21 & 14 & 14 & 35 & 15 & 30 \\
NTH2 & 24 & 21 & 18 & 18 & 12 & 15 & 27 & 10 & 25 \\
L. lactis & & & & & & & & & \\
NTH3 & 30 & 27 & 25 & 21 & 12 & 12 & 23 & 13 & 25 \\
NTH4 & 31 & 27 & 18 & 21 & 10 & 15 & 35 & 15 & 28 \\
NTH5 & 22 & 22 & 19 & 19 & 13 & 16 & 26 & 11 & 25 \\
NTH6 & 22 & 22 & 10 & 15 & 11 & 10 & 24 & 7 & 22 \\
NTH7 & 26 & 25 & 16 & 20 & 10 & 11 & 0 & 11 & 20 \\
NTH8 & 14 & 16 & 12 & 18 & 10 & 25 & 27 & 8 & 24 \\
NTH9 & 23 & 21 & 20 & 20 & 10 & 15 & 25 & 20 & 30 \\
NTH10 & 25 & 25 & 12 & 16 & 12 & 10 & 25 & 8 & 25 \\
\hline
\end{tabular}

Amp ampicillin (10 $\mu \mathrm{g} / \mathrm{disc})$, Chl chloramphenicol (30 $\mu \mathrm{g} / \mathrm{disc})$, Ery erythromycin (15 $\mu \mathrm{g} / \mathrm{disc})$, Van vancomycin $(30 \mu \mathrm{g} / \mathrm{disc})$, Kan kanamycin $(30 \mu \mathrm{g} / \mathrm{disc})$, Gen gentamycin $(10 \mu \mathrm{g} / \mathrm{disc})$, Pen penicillin (10 IU/ disc), Str streptomycin $(10 \mu \mathrm{g} /$ disc $)$, Tet tetracycline $(30 \mu \mathrm{g} / \mathrm{disc})$

${ }^{a}$ The values represent the diameter of the inhibition zone (mm). No inhibition zone: resistant, $<10 \mathrm{~mm}$ : intermediate sensitive, $10-35 \mathrm{~mm}$ : sensitive 
Khemariya et al. (2013) informed that L. lactis strains isolated from dairy and non-dairy sources were susceptible to ampicillin and erythromycin but resistant to kanamycin. In contrast with our results, Flórez et al. (2007) stated that L. lactic strains isolated from dairy and animal sources showed resistance against tetracycline and streptomycin.

From our antibiotic test results, L. lactis NTH7 showed resistance against penicillin, which inhibits cell wall synthesis, where the other strains were sensitive. The resistance to a specific antibiotic may be due to the absence of the target region of the antibiotic in bacterial cell (DeLisle and Perl 2003). On the other hand, L. lactis NTH8 and L. lactis NTH10 were intermediate sensitive to streptomycin, which is a protein synthesis inhibitor, while the other strains showed susceptibility. For safety aspects, the absence of antibiotic resistance in strains to be used as starter or adjunct cultures is of extreme importance. In this study, most of the Lactococcus strains were sensitive to all nine antibiotic tests.

\section{Auto-aggregation ability of Lactococcus strains during $24 \mathrm{~h}(\%)$}

Auto-aggregation values increased from the first hour to the final incubation period (Table 6). The highest autoaggregation numbers were detected for L. lactis NTH7 strain both at the beginning (67.54\%) and the end of the incubation period $(84.96 \%)$ whereas the lowest auto-aggregative strain was L. garvieae NTH1 with $3.22 \%$ and $19.27 \%$ at the initial and last incubation hour, respectively. Four Lactococcus isolates showed less than 50\% auto-aggregation after $24 \mathrm{~h}$. These are higher than that of an earlier report about Lactococcus strains by Abushelaibi et al. (2017) who documented that auto-aggregations of L. lactis KX881768, L. lactis KX881782 and L. garvieae KX881774 were 2.7\%, 25.7\% and $9.0 \%$ after the $24 \mathrm{~h}$, respectively. In this sense, the difference clearly indicated that auto-aggregation varied greatly amongst even the same species. Nonetheless, in the previous studies, several lactic acid bacteria strains had showed high auto-aggregation percentages such as for Lactobacillus casei SM-H (79.8\%) and Pediococcus pentosaceus VJ41 (89\%) (Meira et al. 2012; Vidhyasagar et al. 2013). Aggregation ability is agreed upon as a desirable characteristic of bacterial strains used as probiotics (An et al. 2000). Amongst our Lactococcus isolates, L. lactis NTH7 had a clear advantage for selection as a probiotic as a result of their strong aggregation capability to intestinal cells.

\section{Co-aggregation ability of Lactococcus strains against some pathogenic strains during $\mathbf{3} \mathbf{h}$}

Among these isolates, L. lactis NTH10 and L. lactis NTH9 effectively aggregate with $L$. monocytogenes at $64.97 \%$ and $48.23 \%$ after 3 h, respectively. L. lactis NTH3 showed the highest aggregation ability with $B$. cereus $(38.61 \%)$ (Table 7). On the other hand, L. lactis NTH8 was the lowest aggregative isolate with $S$. aureus (4.24\%) amongst all Lactococcus strains. Co-aggregation values varied greatly among strains belonging to the same species and pathogen microorganisms. Maximum aggregation rates were obtained against $L$. monocytogenes whereas the least aggregation rates were against $S$. aureus. Indeed, in a previous study, Vidhyasagar et al. (2013) reported that five P. pentosaceus

Table 6 Auto-aggregation ability of Lactococcus strains during $24 \mathrm{~h}(\%)$

\begin{tabular}{|c|c|c|c|c|c|}
\hline \multirow[t]{2}{*}{ Isolates } & \multicolumn{5}{|c|}{ Auto-aggregation (\%) } \\
\hline & $1 \mathrm{~h}$ & $2 \mathrm{~h}$ & $3 \mathrm{~h}$ & $4 \mathrm{~h}$ & $24 \mathrm{~h}$ \\
\hline \multicolumn{6}{|c|}{ L. garvieae } \\
\hline NTH1 & $3.22 \pm 0.48^{\mathrm{d}, \mathrm{c}}$ & $3.91 \pm 0.63^{\mathrm{e}, \mathrm{bc}}$ & $4.34 \pm 0.27^{\mathrm{f}, \mathrm{bc}}$ & $6.41 \pm 0.94^{\mathrm{f}, \mathrm{b}}$ & $19.27 \pm 2.28^{\mathrm{d}, \mathrm{a}}$ \\
\hline NTH2 & $15.71 \pm 1.41^{\mathrm{d}, \mathrm{c}}$ & $18.11 \pm 1.63^{\mathrm{c}, \mathrm{bc}}$ & $21.28 \pm 1.44^{\mathrm{e}, \mathrm{ab}}$ & $23.39 \pm 1.54^{\mathrm{e}, \mathrm{a}}$ & $25.49 \pm 2.16^{\mathrm{d}, \mathrm{a}}$ \\
\hline \multicolumn{6}{|l|}{ L. lactis } \\
\hline NTH3 & $38.77 \pm 4.27^{\mathrm{c}, \mathrm{b}}$ & $41.21 \pm 3.36^{\mathrm{c}, \mathrm{b}}$ & $46.38 \pm 5.87^{\mathrm{d}, \mathrm{b}}$ & $51.63 \pm 6.32^{\mathrm{cd}, \mathrm{ab}}$ & $64.38 \pm 8.77^{\mathrm{bc}, \mathrm{a}}$ \\
\hline NTH4 & $45.85 \pm 6.38^{\mathrm{bc}, \mathrm{ns}}$ & $47.33 \pm 5.47^{\mathrm{c}, \mathrm{ns}}$ & $48.61 \pm 5.51^{\mathrm{cd}, \mathrm{ns}}$ & $51.22 \pm 4.28^{\mathrm{cd}, \mathrm{ns}}$ & $59.63 \pm 7.68^{\mathrm{c}, \mathrm{ns}}$ \\
\hline NTH5 & $10.25 \pm 2.21^{\mathrm{d}, \mathrm{b}}$ & $12.32 \pm 1.47^{\mathrm{de}, \mathrm{b}}$ & $14.61 \pm 1.96^{\mathrm{ef}, \mathrm{b}}$ & $16.87 \pm 3.37^{\text {ef, b }}$ & $26.94 \pm 5.47^{\mathrm{d}, \mathrm{a}}$ \\
\hline NTH6 & $15.62 \pm 1.38^{\mathrm{d}, \mathrm{c}}$ & $18.06 \pm 2.94^{\mathrm{d}, \mathrm{bc}}$ & $19.42 \pm 3.03^{\mathrm{e}, \mathrm{bc}}$ & $24.32 \pm 0.98^{\mathrm{e}, \mathrm{b}}$ & $33.66 \pm 4.72^{\mathrm{d}, \mathrm{a}}$ \\
\hline NTH7 & $67.54 \pm 7.78^{\mathrm{a}, \mathrm{b}}$ & $70.14 \pm 5.43^{\mathrm{a}, \mathrm{ab}}$ & $73.47 \pm 6.97^{\mathrm{a}, \mathrm{ab}}$ & $77.06 \pm 5.18^{\mathrm{a}, \mathrm{ab}}$ & $84.96 \pm 4.39^{\mathrm{a}, \mathrm{a}}$ \\
\hline NTH8 & $57.00 \pm 4.81^{\mathrm{ab}, \mathrm{ns}}$ & $59.22 \pm 3.74^{\mathrm{b}, \mathrm{ns}}$ & $60.38 \pm 2.41^{\mathrm{bc}, \mathrm{ns}}$ & $62.17 \pm 6.31^{\mathrm{bc}, \mathrm{ns}}$ & $69.47 \pm 6.87^{\mathrm{abc}, \mathrm{ns}}$ \\
\hline NTH9 & $40.65 \pm 3.56^{\mathrm{c}, \mathrm{b}}$ & $42.04 \pm 4.88^{\mathrm{c}, \mathrm{b}}$ & $44.57 \pm 5.37^{\mathrm{d}, \mathrm{b}}$ & $46.93 \pm 5.07^{\mathrm{d}, \mathrm{ab}}$ & $59.66 \pm 6.07^{\mathrm{c}, \mathrm{a}}$ \\
\hline NTH10 & $62.66 \pm 5.34^{\mathrm{a}, \mathrm{ns}}$ & $65.34 \pm 3.86^{\mathrm{ab}, \mathrm{ns}}$ & $67.08 \pm 4.71^{\mathrm{ab}, \mathrm{ns}}$ & $69.84 \pm 8.14^{\mathrm{ab}, \mathrm{ns}}$ & $78.09 \pm 7.52^{\mathrm{ab}, \mathrm{ns}}$ \\
\hline
\end{tabular}

Different letters in the same row and column are significantly different $(P<0.05)$

First letters present differences between the strains and second letters demonstrate the differences between the times ns not significantly different 
Table 7 Co-aggregation ability of Lactococcus strains against pathogenic strains during $3 \mathrm{~h}(\%)$

Co-aggregation with $B$. cereus (\%)

$\begin{array}{llll}\text { Isolates* }^{*} & 1 \mathrm{~h} & 2 \mathrm{~h} & 3 \mathrm{~h} \\ \text { NTH1 } & 12.41 \pm 2.16^{\mathrm{b}, \mathrm{b}} & 14.32 \pm 1.88^{\mathrm{b}, \mathrm{b}} & 26.47 \pm 3.96^{\mathrm{ns}, \mathrm{a}} \\ \text { NTH3 } & 27.36 \pm 5.22^{\mathrm{a}, \mathrm{ns}} & 29.38 \pm 4.25^{\mathrm{a}, \mathrm{ns}} & 38.61 \pm 6.63^{\mathrm{ns}, \mathrm{ns}}\end{array}$

Co-aggregation with $S$. typhimurium (\%)

\begin{tabular}{|c|c|c|c|}
\hline & $1 \mathrm{~h}$ & $2 \mathrm{~h}$ & $3 \mathrm{~h}$ \\
\hline NTH4 & $17.25 \pm 0.69^{\mathrm{a}, \mathrm{b}}$ & $19.72 \pm 1.56^{\mathrm{a}, \mathrm{b}}$ & $24.37 \pm 2.16^{\mathrm{ns}, \mathrm{a}}$ \\
\hline NTH5 & $11.08 \pm 2.51^{\mathrm{b}, \mathrm{b}}$ & $14.16 \pm 1.54^{\mathrm{b}, \mathrm{ab}}$ & $20.11 \pm 3.43^{\text {ns, a }}$ \\
\hline \multicolumn{4}{|c|}{ Co-aggregation with $E$. coli $(\%)$} \\
\hline & $1 \mathrm{~h}$ & $2 \mathrm{~h}$ & $3 \mathrm{~h}$ \\
\hline NTH6 & $20.34 \pm 3.18^{\mathrm{a}, \mathrm{ns}}$ & $24.54 \pm 4.73^{\mathrm{a}, \mathrm{ns}}$ & $32.18 \pm 5.77^{\mathrm{a}, \mathrm{ns}}$ \\
\hline NTH2 & $7.00 \pm 2.11^{\mathrm{b}, \mathrm{b}}$ & $9.12 \pm 1.94^{\mathrm{b}, \mathrm{b}}$ & $16.38 \pm 4.19^{\mathrm{b}, \mathrm{a}}$ \\
\hline \multicolumn{4}{|c|}{ Co-aggregation with S. aureus (\%) } \\
\hline & $1 \mathrm{~h}$ & $2 \mathrm{~h}$ & $3 \mathrm{~h}$ \\
\hline NTH7 & $7.11 \pm 1.33^{\mathrm{a}, \mathrm{ns}}$ & $8.19 \pm 2.10^{\mathrm{a}, \mathrm{ns}}$ & $10.34 \pm 2.69^{\mathrm{a}, \mathrm{ns}}$ \\
\hline NTH8 & $2.11 \pm 0.21^{\mathrm{b}, \mathrm{c}}$ & $3.08 \pm 0.52^{\mathrm{b}, \mathrm{b}}$ & $4.24 \pm 0.17^{\mathrm{b}, \mathrm{a}}$ \\
\hline \multicolumn{4}{|c|}{ Co-aggregation with L. monocytogenes (\%) } \\
\hline & $1 \mathrm{~h}$ & $2 \mathrm{~h}$ & $3 \mathrm{~h}$ \\
\hline NTH9 & $30.18 \pm 2.46^{\mathrm{b}, \mathrm{b}}$ & $37.04 \pm 5.78^{\mathrm{b}, \mathrm{ab}}$ & $48.23 \pm 6.67^{\mathrm{ns}, \mathrm{a}}$ \\
\hline NTH10 & $52.27 \pm 3.74^{\mathrm{a}, \mathrm{ns}}$ & $55.29 \pm 2.89^{\mathrm{a}, \mathrm{ns}}$ & $64.97 \pm 8.19^{\mathrm{ns}, \mathrm{n}}$ \\
\hline
\end{tabular}

*NTH1 and NTH2 strains belong to L. garvieae, NTH3-10 strains pertain to L. lactis

Different letters in the same row and column are significantly different $(P<0.05)$

First letters present differences between the strains and second letters demonstrate the differences between the times

$n s$ not significantly different

isolates showed the highest co-aggregation values (between $86 \%$ and $90 \%$ ) against L. monocytogenes compared to the other indicator bacteria. Similarly, Abushelaibi et al. (2017) reported that L. lactis KX881768 and L. lactis KX881782 showed significantly lower co-aggregation percentages with $S$. aureus after $2 \mathrm{~h}$ in comparing with the other pathogens such as E. coli 0157: H7, S. typhimurium and L. monocytogenes. Co-aggregation represents an obstacle to preserve intestine wall surface colonization of pathogenic bacteria, thus advantageous in supporting instead the adherence of beneficial microorganisms. The adhesion of lactic cultures to intestine epithelium is a prerequisite characteristic for probiotic bacteria. Among our isolates, L. lactis NTH10 and L. lactis NTH9 complied with this criterion better than the other tested Lactococcus strains.

\section{EPS, diacetyl and $\mathrm{H}_{2} \mathrm{O}_{2}$ production of Lactococcus strains}

Based on EPS test, all Lactococcus isolates were positive for EPS production in the present study (Table 8). This result is in an agreement with those reported by Abushelaibi et al. (2017) who indicated a satisfactory EPS producing ability for three tested Lactococcus isolates (L. lactis KX881768, L. lactis KX881782 and L. garvieae KX881774) in their study. However, results from our study contradicted a previous study executed by Franciosi et al. (2009) who claimed that none of their 30 Lactococcus isolates could produce EPS. Exopolysaccharides have significant commercial value by means of their industrially useful physico-chemical features; hence, EPS-forming bacteria play an important role in the rheology and texture of fermented food products (Patel et al. 2012). In this sense, EPS-forming capability is taken into consideration in the selection of starter and adjunct cultures, so all these Lactococcus isolates have a considerable industrial use potential in the manufacturing of several dairy products.

In tests for diacetyl production, only four Lactococcus isolates (L. garvieae NTH1, L. garvieae NTH2, L. lactis NTH7 and L. lactis NTH10) exhibited the ability to produce diacetyl (Table 8), and this is in accordance with a previous study which displayed diacetyl production, and the amount of Lactococcus isolates was strain-dependent (Franciosi et al. 2009). These researchers observed that only ten isolates produced diacetyl amongst 30 Lactococcus isolates. On the other hand, Kondrotiene et al. (2018) reported that none of the 12 Lactococcus lactis isolates were able to produce diacetyl. Diacetyl is a volatile compound produced by some LAB as an end product of citrate metabolism and directly linked to good aroma formation. Thus, these four Lactococcus isolates can be used for the application as starter or adjunct cultures.

Regarding $\mathrm{H}_{2} \mathrm{O}_{2}$ production, all Lactococcus isolates used in this study generated different amounts of $\mathrm{H}_{2} \mathrm{O}_{2}$ from each other (Table 8). Several researchers have reported different findings with regard to $\mathrm{H}_{2} \mathrm{O}_{2}$ production of various Lactococcus strains, such as Yüksekdağ et al. (2004) who determined that three out of four isolates of L. lactis were

Table 8 EPS, diacetyl and $\mathrm{H}_{2} \mathrm{O}_{2}$ production of Lactococcus strains

\begin{tabular}{llll}
\hline Isolates & EPS production & Diacetyl production & $\mathrm{H}_{2} \mathrm{O}_{2}$ production \\
\hline L. garvieae & & & \\
$\mathrm{NTH} 1$ & + & + & + \\
$\mathrm{NTH} 2$ & + & + & + \\
L. lactis & & & \\
NTH3 & + & - & + \\
NTH4 & + & - & + \\
NTH5 & + & - & + \\
NTH6 & + & - & + \\
NTH7 & + & + & + \\
NTH8 & + & - & + \\
NTH9 & + & - & + \\
NTH10 & + & + & + \\
\hline
\end{tabular}

“-” negative, “+” positive 
$\mathrm{H}_{2} \mathrm{O}_{2}$ producers. It has also been observed that 21 out of 77 Lactococcus isolates from Andalusian raw goat milk were able to produce $\mathrm{H}_{2} \mathrm{O}_{2}$ (Picon et al. 2016). $\mathrm{H}_{2} \mathrm{O}_{2}$ supports bactericidal activity to prolong shelf life, delays/contrasts food spoilage and diminishes pathogenic microorganisms and their detrimental effects. $\mathrm{H}_{2} \mathrm{O}_{2}$ produced by $\mathrm{LAB}$ might be, therefore, an important part of the fermentation process. Considering the $\mathrm{H}_{2} \mathrm{O}_{2}$ production of the tested Lactococcus strains, all isolates are good candidates for commercial culture use.

\section{Growth studies}

The ability of lactic cultures to survive in adequate amount after subjected to low or high temperatures is an important feature for their use in the food industry. Survival at 15 and $45{ }^{\circ} \mathrm{C}$ of tested Lactococcus strains changed mostly due to strain specificity; however, no growth was observed for all tested strains at $4{ }^{\circ} \mathrm{C}$ (Table 9). L. lactis NTH8 showed greater growth (++) among the four Lactococcus isolates which were able to grow at $45^{\circ} \mathrm{C}$ while all tested isolates revealed similar growth at $15{ }^{\circ} \mathrm{C}(+)$. The low percentage of lactococci that were able to grow at $45{ }^{\circ} \mathrm{C}$ is in agreement with results by Franciosi et al. (2009) which stated that 2 out of 14 L. lactis subsp. lactis isolates, 1 isolate out of $11 \mathrm{~L}$. lactis subsp. cremoris and 2 out of 5 L. garvieae isolates displayed growth at this temperature. Badis et al. (2004) also revealed that all 46 L. lactis and 2 L. garvieae isolates exhibited no growth at $45{ }^{\circ} \mathrm{C}$

Most strains exhibited high growth in the presence of ethanol with the exception of L. lactis NTH10 which demonstrated no tolerance above $6 \%$ alcohol concentration (Table 9). Among the isolates tested in this study, L. lactis NTH7 strain had the highest ethanol resistance; surprisingly, this isolate grew very well even at high alcohol concentrations of $12 \%$, thereby demonstrating the potential of L. lactis NTH7 to resist ethanol. When determining a durable microorganism to harsh conditions for production of ethanol, it is judicious to choose one that shows a higher tolerance to ethanol. Generally, ethanol tolerance of lactic acid bacteria (LAB) is known to be high, but previous studies were commonly executed using Lactobacillus strains, for this reason limited data exists regarding Lactococcus strains and their ethanol tolerance. In a recent study, Hviid et al. (2017) claimed that high concentrations of ethanol were cytostatic to L. lactis. While Solem et al. (2013) determined that the wild-type L. lactis strain MG1363 grew, although slowly, in the presence of $6 \%$ ethanol and mutant derivative L. lactis strain MG1363 were capable of growth in the presence of $\% 8$ ethanol.

All Lactococcus isolates tolerated up to $10 \%$ salt and generally displayed high growth in all $\mathrm{NaCl}$ concentrations used in this study, whereas the highest growth was observed in L. lactis NTH4, even in the presence of $10 \%$ salt (Table 9).
These findings indicated that Lactococcus isolates in the present study are likely to grow best under high salt concentrations and have the potential for use in manufacturing of several cheeses containing high salt levels, especially L. lactis NTH4. Our results are in contrast with that of Cogan et al. (1997) and Karakas-Sen and Karakas (2018) who revealed that some wild-type L. lactis subsp. lactis strains grew weakly in media consisting of $6.5 \% \mathrm{NaCl}$. On the other hand, our results are in an agreement with those reported by de Almeida Júnior et al. (2015) who claimed that 9 out of the 13 L. lactis isolates were able to produce good growth at $6.5 \%$ $\mathrm{NaCl}$. Obis et al. (2001) claimed that several strains of L. lactis subsp. lactis and cremoris grew well in 6.5\% (w/v) salt concentrations, but growth of some other strains was negatively affected even at $2 \%(w / v) \mathrm{NaCl}$. In this sense, the differences in results could have been caused by the different strains used in all studies.

Regarding $\mathrm{H}_{2} \mathrm{O}_{2}$ resistance, growth of Lactococcus strains in $\mathrm{M} 17$ broth decreased with the increasing exposure ratio to $\mathrm{H}_{2} \mathrm{O}_{2}$ (Table 9). This is not surprising since oxidative stress often may result in DNA and cell membrane damage and weaken the bacteria. Lactococcus strains like other lactic acid bacteria are very sensitive to $\mathrm{H}_{2} \mathrm{O}_{2}$ because they lack the catalase activity to reduce $\mathrm{H}_{2} \mathrm{O}_{2}$ into water and oxygen (Rochat et al. 2005). There is an obvious consensus about hydrogen peroxide as an important inhibitor for lactococci (Piard and Desmazeaud 1992). Among all Lactococcus isolates, the highest $\mathrm{H}_{2} \mathrm{O}_{2}$ tolerance was displayed by L. lactis NTH8, L. lactis NTH5 and $L$. garvieae NTH2, whereas the most vulnerable isolate to all $\mathrm{H}_{2} \mathrm{O}_{2}$ levels was L. lactis NTH3. Thus, this tolerance was observed to be strain-dependent. Similar results were also noted earlier by Piard and Desmazeaud (1992), who stated that autoinhibition by $\mathrm{H}_{2} \mathrm{O}_{2}$ is not universal among Lactococcus strains.

\section{Conclusions}

The present study was undertaken to identify suitable probiotic Lactococcus strains isolated from traditional goatskin casings of Tulum cheeses from the Central Taurus mountain range in Turkey. These results are a precursor to future in vivo trials. Regarding acid tolerance, antibiotic susceptibility, survival rates during simulated gastric juice, autoaggregation and co- aggregation ability scores, EPS, diacetyl and $\mathrm{H}_{2} \mathrm{O}_{2}$ production L. lactis $\mathrm{NTH} 10$ exhibited satisfactory in vitro probiotic properties and had a good potential to be used as a probiotic microorganism. Further studies should be required to clearly claim $L$. lactis $\mathrm{NTH10}$ as a probiotic strain and focus on improving the technological characteristics for industrial applications. 


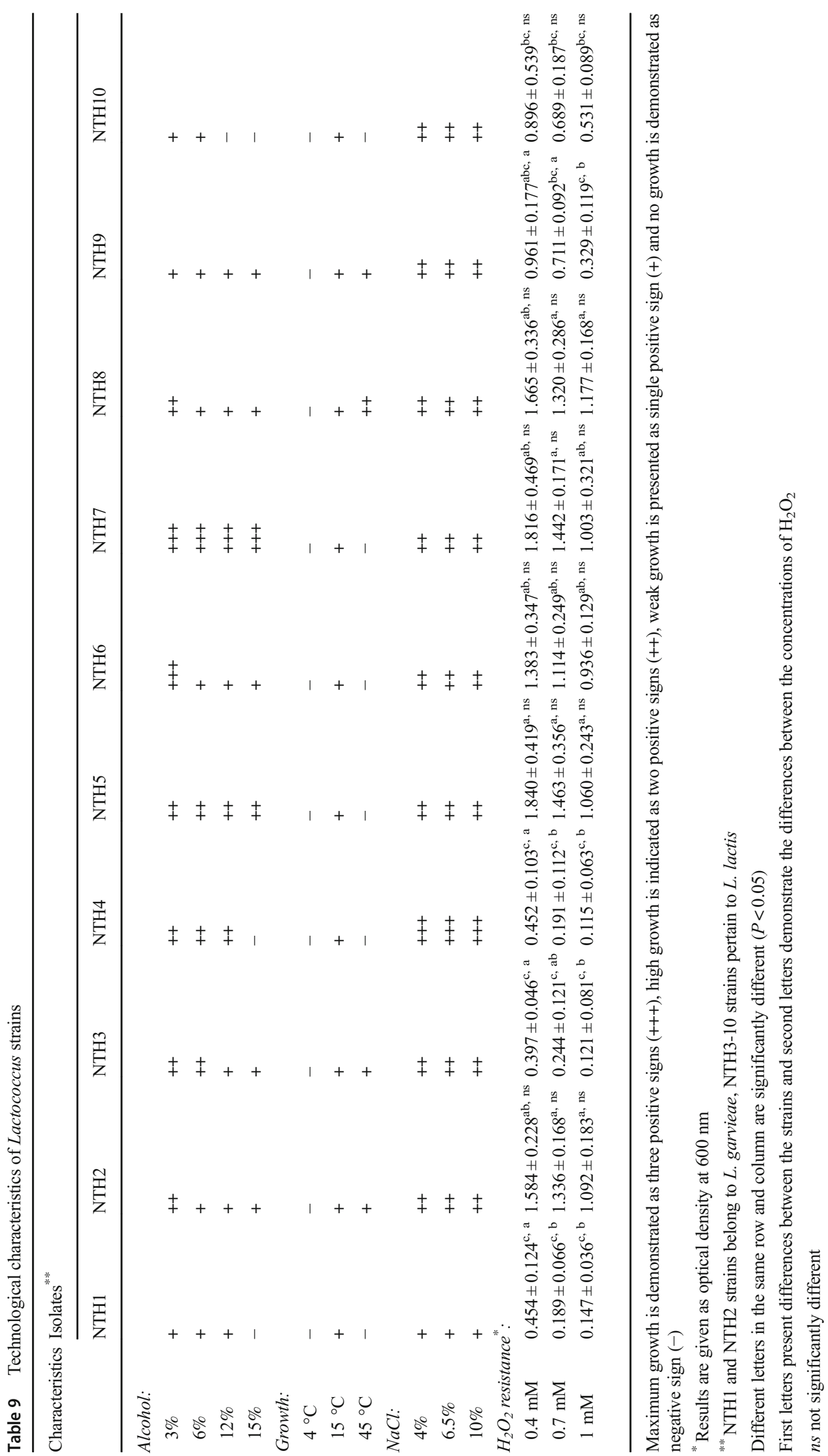


Funding information TUBITAK (Scientific and Technological Research Council of Turkey) supported the isolation and identification of Lactococcus strains from traditional Turkish skin bag Tulum cheeses by the project number TOAG-214Z054.

\section{Compliance with ethical standards}

Conflict of interest The authors declare that they have no conflict of interest.

\section{Research involving human participants and/or animals Not applicable.}

Informed consent Informed consent was obtained from all individual participants included in the study.

\section{References}

Abushelaibi A, Al-Mahadin S, El-Tarabily K, Shah NP, Ayyash M (2017) Characterization of potential probiotic lactic acid bacteria isolated from camel milk. LWT-Food Sci Technol 79:316-325

Adamberg K, Kask S, Laht T-M, Paalme T (2003) The effect of temperature and $\mathrm{pH}$ on the growth of lactic acid bacteria: a $\mathrm{pH}$-auxostat study. Int J Food Microbiol 85:171-183

An YH, Dickinson RB, Doyle RJ (2000) Mechanisms of bacterial adhesion and pathogenesis of implant and tissue infections. Handbook of Bacterial Adhesion. Springer, In, pp 1-27

Attar MA, Yavarmanesh M, Mortazavi A, Dovom MRE, Najafi MBH (2018) Antibacterial effects of Lactococcus lactis isolated from Lighvan cheese regarding the recognition of Nisin, Lacticin and Lactococcin structural genes. LWT-Food Sci Technol 89:186-191

Badis A, Guetarni D, Boudjema BM, Henni D, Kihal M (2004) Identification and technological properties of lactic acid bacteria isolated from raw goat milk of four Algerian races. Food Microbiol 21:579-588

Bao Y et al (2010) Screening of potential probiotic properties of Lactobacillus fermentum isolated from traditional dairy products. Food Control 21:695-701

Bautista-Gallego J, Arroyo-López F, Rantsiou K, Jiménez-Díaz R, Garrido-Fernández A, Cocolin L (2013) Screening of lactic acid bacteria isolated from fermented table olives with probiotic potential. Food Res Int 50:135-142

Bengoa AA, Llamas MG, Iraporda C, Dueñas MT, Abraham AG, Garrote GL (2018) Impact of growth temperature on exopolysaccharide production and probiotic properties of Lactobacillus paracasei strains isolated from kefir grains. Food Microbiol 69:212-218

Cakmakci S, Dagdemir E, Hayaloglu A, Gurses M, Gundogdu E (2008) Influence of ripening container on the lactic acid bacteria population in Tulum cheese. World J Microbiol Biotechnol 24:293-299

Chalas R, Janczarek M, Bachanek T, Mazur E, Cieszko-Buk M, Szymanska J (2016) Characteristics of oral probiotics-a review. Curr Issues Pharm Med Sci 29:8-10

Charteris WP, Kelly MP, Morelli L, Collins KJ (1998a) Antibiotic susceptibility of potentially probiotic Lactobacillus species. Journal Food Prot 61(12):1636-1164

Charteris WP, Kelly MP, Morelli L, Collins KJ (1998b) Development and application of an in vitro methodology to determine the transit tolerance of potentially probiotic Lactobacillus and Bifidobacterium species in the upper human gastrointestinal tract. J Appl Microbiol 84:759-768

Cogan TM et al (1997) Characterization of the lactic acid bacteria in artisanal dairy products. J Dairy Res 64:409-421
Collins MD, Gibson GR (1999) Probiotics, prebiotics, and synbiotics: approaches for modulating the microbial ecology of the gut. Am J Clin Nutr 69:1052s-1057s

Danielsen M, Wind A (2003) Susceptibility of Lactobacillus spp. to antimicrobial agents. Int J Food Microbiol 82(1):1-11

Das P, Khowala S, Biswas S (2016) In vitro probiotic characterization of Lactobacillus casei isolated from marine samples. LWT-Food Sci Technol 73:383-390

de Almeida Júnior WLG, da Silva FÍ, de Souza JV, da Silva CDA, da Costa MM, Dias FS (2015) Characterization and evaluation of lactic acid bacteria isolated from goat milk. Food Control 53:96-103

DeLisle S, Perl TM (2003) Vancomycin-resistant enterococci: a road map on how to prevent the emergence and transmission of antimicrobial resistance. Chest 123(5):504S-518S

Domingos-Lopes M, Stanton C, Ross P, Dapkevicius M, Silva C (2017) Genetic diversity, safety and technological characterization of lactic acid bacteria isolated from artisanal Pico cheese. Food Microbiol 63: $178-190$

FAO/WHO (2001) Report of a joint FAO/WHO expert consultation on evaluation of health and nutritional properties of probiotics in food including powder milk with live lactic acid bacteria. Córdoba

Faye T, Tamburello A, Vegarud GE, Skeie S (2012) Survival of lactic acid bacteria from fermented milks in an in vitro digestion model exploiting sequential incubation in human gastric and duodenum juice. J Dairy Sci 95:558-566

Flórez AB, Danielsen M, Korhonen J, Zycka J, von Wright A, Bardowski J, Mayo B (2007) Antibiotic survey of Lactococcus lactis strains to six antibiotics by Etest, and establishment of new susceptibilityresistance cut-off values. J Dairy Res 74(3):262-268

Franciosi E, Settanni L, Cavazza A, Poznanski E (2009) Biodiversity and technological potential of wild lactic acid bacteria from raw cows' milk. Int Dairy J 19:3-11

G-Alegría E et al (2004) High tolerance of wild Lactobacillus plantarum and Oenococcus oeni strains to lyophilisation and stress environmental conditions of acid $\mathrm{pH}$ and ethanol. FEMS Microbiol Lett 230:53-61

Gurses M, Erdogan A (2006) Identification of lactic acid bacteria isolated from Tulum cheese during ripening period. Int J Food Prop 9:551557

Hoque M, Akter F, Hossain K, Rahman M, Billah M, Islam K (2010) Isolation, identification and analysis of probiotic properties of Lactobacillus spp. from selective regional yoghurts. World J Dairy Food Sci 5:39-46

Hviid A-MM, Ruhdal-Jensen P, Kilstrup M (2017) Butanol is cytotoxic to Lactococcus lactis while ethanol and hexanol are cytostatic. Microbiol 163:453-461

Karakas-Sen A, Karakas E (2018) Isolation, identification and technological properties of lactic acid bacteria from raw cow milk. Biosci J 34: 385-399

Khemariya P, Singh S, Nath G, Gulati AK (2013) Isolation, identification and antibiotic susceptibility of nis+ Lactococcus lactis from dairy and non-dairy sources. Czech J Food Sci 31(4):323-331

Kimoto H, Kurisaki J, Tsuji N, Ohmomo S, Okamoto T (1999) Lactococci as probiotic strains: adhesion to human enterocyte-like Caco-2 cells and tolerance to low $\mathrm{pH}$ and bile. Lett Appl Microbiol 29:313-316

Kondrotiene K et al (2018) Characterization and application of newly isolated nisin producing Lactococcus lactis strains for control of Listeria monocytogenes growth in fresh cheese. LWT-Food Sci Technol 87:507-514

Kos B, Šušković J, Vuković S, Šimpraga M, Frece J, Matošić S (2003) Adhesion and aggregation ability of probiotic strain Lactobacillus acidophilus M92. J Appl Microbiol 94:981-987

Kumar BV, Vijayendra SVN, Reddy OVS (2015) Trends in dairy and non-dairy probiotic products-a review. J Food Sci Technol 52:61126124 
Li S et al (2012) Antioxidant activity of Lactobacillus plantarum strains isolated from traditional Chinese fermented foods. Food Chem 135: 1914-1919

Lopez-Diaz T, Alonso C, Roman C, Garcia-Lopez M, Moreno B (2000) Lactic acid bacteria isolated from a hand-made blue cheese. Food Microbiol 17:23-32

Meira SMM, Helfer VE, Velho RV, Lopes FC, Brandelli A (2012) Probiotic potential of Lactobacillus spp. isolated from Brazilian regional ovine cheese. J Dairy Res 79:119-127

Mishra V, Prasad D (2005) Application of in vitro methods for selection of Lactobacillus casei strains as potential probiotics. Int J Food Microbiol 103:109-115

Obis D, Guillot A, Mistou MY (2001) Tolerance to high osmolality of Lactococcus lactis subsp. lactis and cremoris is related to the activity of a betaine transport system. FEMS Microbiol Lett 202:39-44

Ooi L-G, Liong M-T (2010) Cholesterol-lowering effects of probiotics and prebiotics: a review of in vivo and in vitro findings. Int J Mol Sci 11:2499-2522

Patel A, Lindström C, Patel A, Prajapati J, Holst O (2012) Probiotic properties of exopolysaccharide producing lactic acid bacteria isolated from vegetables and traditional Indian fermented foods. Int J Fermented Foods 1:87-101

Patrick WA, Wagner HB (1949) Determination of hydrogen peroxide in small concentrations. Anal Chem 21:1279-1280

Piard J, Desmazeaud M (1992) Inhibiting factors produced by lactic acid bacteria. 2. Bacteriocins and other antibacterial substances. Lait 72: $113-142$

Picon A, Garde S, Ávila M, Nuñez M (2016) Microbiota dynamics and lactic acid bacteria biodiversity in raw goat milk cheeses. Int Dairy J 58:14-22

Prasad J, Gill H, Smart J, Gopal PK (1998) Selection and characterisation of Lactobacillus and Bifidobacterium strains for use as probiotics. Int Dairy J 8:993-1002

Randazzo CL, Vaughan EE, Caggia C (2006) Artisanal and experimental pecorino Siciliano cheese: microbial dynamics during manufacture assessed by culturing and PCR-DGGE analyses. Int J Food Microbiol 109:1-8

Ribeiro S, Coelho M, Todorov S, Franco B, Dapkevicius M, Silva C (2014) Technological properties of bacteriocin-producing lactic acid bacteria isolated from Pico cheese an artisanal cow's milk cheese. J Appl Microbiol 116:573-585

Rochat T, Miyoshi A, Gratadoux J, Duwat P, Sourice S, Azevedo V, Langella P (2005) High-level resistance to oxidative stress in Lactococcus lactis conferred by Bacillus subtilis catalase KatE. Microbiol 151:3011-3018
Rodgers S (2008) Novel applications of live bacteria in food services: probiotics and protective cultures. Trends Food Sci Technol 19:188197

Sabir F, Beyatli Y, Cokmus C, Onal-Darilmaz D (2010) Assessment of potential probiotic properties of Lactobacillus spp., Lactococcus spp., and Pediococcus spp. strains isolated from kefir. J Food Sci 75:M568-M573

Shehata M, El Sohaimy S, El-Sahn MA, Youssef M (2016) Screening of isolated potential probiotic lactic acid bacteria for cholesterol lowering property and bile salt hydrolase activity. Ann Clin Lab Sci 61: 65-75

Solem C, Dehli T, Jensen PR (2013) Rewiring Lactococcus lactis for ethanol production. J Appl Environ Microbiol 79:2512-2518

Takeda S et al (2011) The investigation of probiotic potential of lactic acid bacteria isolated from traditional Mongolian dairy products. Animal Sci J 82:571-579

Tambekar D, Bhutada S (2010) Studies on antimicrobial activity and characteristics of bacteriocins produced by Lactobacillus strains isolated from milk of domestic animals. Internet J Microbiol 8:1-6

Tulumoğlu Ș, Kaya Hİ, Șimșek Ö (2014) Probiotic characteristics of Lactobacillus fermentum strains isolated from tulum cheese. Anaerobe 30:120-125

Umer Khan S (2014) Probiotics in dairy foods: a review Nutrition \& Food Science 44:71-88

Van Geel-Schutten G, Flesch F, Ten Brink B, Smith M, Dijkhuizen L (1998) Screening and characterization of Lactobacillus strains producing large amounts of exopolysaccharides. Appl Microbiol Biotechnol 50:697-703

Vidhyasagar V, Saraniya A, Jeevaratnam K (2013) Identification of pectin degrading lactic acid bacteria from fermented food sources. Int $\mathrm{J}$ Adv Lif Sci 6:8-12

Vinderola C, Reinheimer J (2003) Lactic acid starter and probiotic bacteria: a comparative "in vitro" study of probiotic characteristics and biological barrier resistance. Food Res Int 36:895-904

Weichselbaum E (2009) Probiotics and health: a review of the evidence. Nutr Bull 34:340-373

Yüksekdağ Z, Beyatli Y, Aslim B (2004) Determination of some characteristics coccoid forms of lactic acid bacteria isolated from Turkish kefirs with natural probiotic. LWT-Food Sci Technol 37:663-667

Publisher's note Springer Nature remains neutral with regard to jurisdictional claims in published maps and institutional affiliations. 